\title{
Measuring the Torque of a Combustion Engine.
}

\author{
Josef Popelka ${ }^{1}$, Celestýn Scholz ${ }^{1}$ \\ ${ }^{1}$ technical University of Liberec, Studentská 1402/2, Liberec, Czech Republic,
}

\begin{abstract}
This paper deals with the measurement of torque using a designed torque sensor. To determine the indicated engine parameters, the torque along with the torque in the combustion space of the individual cylinders are measured. I worked on the measured values to determine the dependence of the torque moments on the engine load. The obtained data was used to assess the possible use for further measurements.
\end{abstract}

\section{Introduction}

Over the past few decades, the requirements and criteria that must be met by car manufacturers are constantly increasing. Legislators have considerably contributed to this by directly influencing production in the individual sectors through the creation of various emission regulations and standards. The other side of the coin is the price, which is of interest to the end consumer. In addition to price, potential customers are interested in the parameters of the vehicle, such as consumption and the quantity of pollutants produced. Of course, these two parameters are directly proportional to the performance parameters and, therefore, a reasonable compromise needs to be found. Car makers, of course, are searching for more ways of achieving better performance with lower or equal consumption. As a way of saving power or fuel, a direct option is to reduce internal engine losses. In order to understand this issue and reduce losses as much as possible, there is no suitable measurement method at present.

\section{Basic methods for measuring torque}

Torque measuring methods are divided into two basic groups:

- Indirect torque measure

- Direct torque measure (Measure using torque or force sensor)

- Special way (Combination)

\subsection{Indirect torque measure}

\subsubsection{Torque measure with electric machine.}

In case when combustion engine is connected to electric generator is the possibility to measure power, respectively torque by measuring of voltage, current and
RPMs of electric machine. Using of this method is not very common because measure is influenced by significant error of measurement a lot of physical quality. If we improve this measure by adding a torque sensor we can use electric generator to put load on the engine which is proper and common use alternative.

\subsubsection{Torque measure with piezoelectric pressure sensor.}

This method is an exclusive solution by AVL Company and it is mostly used for the special measuring powertrain stands or engine dynamometers. Method measures pressure directly with pressure sensors inside the combustion chamber. If we put normal force into piezoelectric sensor's silicon plate it generates electric charge which is direct proportional to force. We need a characteristic indicated pressure depended on crank shaft angle to get characteristic of indicated torque. We use incremental sensor connected to crankshaft to determinate its angle. To get effective torque we need to know friction moment and inertia moment of the engine. [3], [4]

\subsubsection{Torque determination from inertia moment.}

We can determinate engine's power, respectively torque by measuring RMPs and time needed to spin body of known inertia moment. It is the simplest measuring technique and nowadays it is just used at amateur conditions because of great error in measurement. It cannot be used during long-term measure. It can be used as comparison method with some success.

\subsection{Direct torque measure (Measure using torque or force sensor)}

Measure using torque sensors is mostly used of its accuracy and repeatability. Principe is based on the direct 
torque measure. Differences between each type of sensor are in physical method used for torque measure.

Most of torque sensor is using shaft as a deformation element. Differences between these sensors are that some uses own shaft and others use shaft from measured device. Second option can by inaccurate sometimes. [1], [5], [6]

Torque sensors types:

- Resistive sensor

- Induction sensor

- Capacitive sensor

\subsubsection{Resistive sensors}

Resistive sensors are most widespread with simply construction. Measure is based on deformation of measuring element which is shaft in most cases. Sensors can be divided into two groups. First one uses own shafts putted into measuring track. Second one uses shaft of measured device. [1], [5], [6]

\subsubsection{Sensor with resistive potentiometer.}

Its function is based on angle deviation of measured shaft. Sensor requires significant deformations of measured element. Sensor electronic transforms a resistivity into electric signal that is directly proportional by sensor's deformation. [1], [5], [6]

\subsubsection{Sensor with resistive tensometer.}

Sensor principle is based on the measure of shear stress with tensometer. Tensometer is very often used sensor because of no requirement of measuring element. Unfortunately is necessary to solve signal transmission from rotating part. Measured element is mostly cylinder shape part with several glued tensometer by $45^{\circ}$ angle to axis of rotation. This assemble creates so called tensometric bridge. [1], [5], [6]

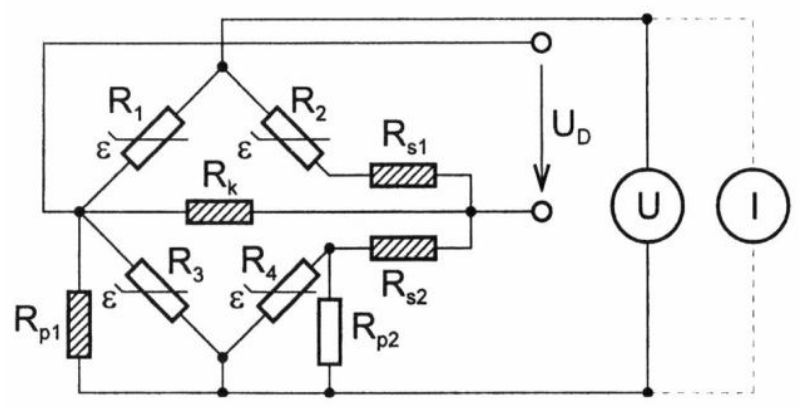

Figure 1. Schema of Tensometric Bridge [1]

\subsubsection{Induction sensor.}

Induction sensor got small air cavity. Angle deviation of shaft is dependable on air cavity change. Sensor's coil is placed on the stator part, which also solve signal transmission from rotating shaft.

\subsubsection{Capacitive sensor.}

Capacitive sensor is made from two tooth shaped electrodes which are bonded into a shaft with enough tooth space. Shaft deformation causes decreasing of the tooth space by electrode rotation which leads into change of capacitive. One of electrodes has to be perfectly isolated from the shaft otherwise capacity will not change. [1], [5], [6]

\subsection{Measuring torque by measuring the force on a known arm}

This is a sophisticated method based on measuring the reaction in the storage of the measured unit. The method s commonly used, for example, with older types of dynamometers. An advantage is the simplicity of the measuring device, and a disadvantage is measuring errors affected by the storage of the measured unit. [1]

\section{Design of measuring devices for monitoring engine torque}

From the principle of torque measurement, we offer two solutions for obtaining the torque directly from the engine. The simplest solution is to use a suitable cylindrical part, such as a flywheel, to which strain gauges are attached. This method can be used to measure the surface tension on the selected part in order to determine the torque. Unfortunately, this method has several pitfalls. Probably the largest one is the signal transmission from the rotating part. Another is the very tight space for attaching the strain gauges and the harsh environment between the engine and the gearbox, mainly in terms of temperature. The last important factor is the lack of experience with attaching and subsequently using the strain gauges. The second solution involves the use of industriallymanufactured measuring elements. In our case, the measuring flange is the most suitable. A significant disadvantage of this solution is the installation dimensions of the flange, but we have a functional and tested measuring element that can be used. [4]

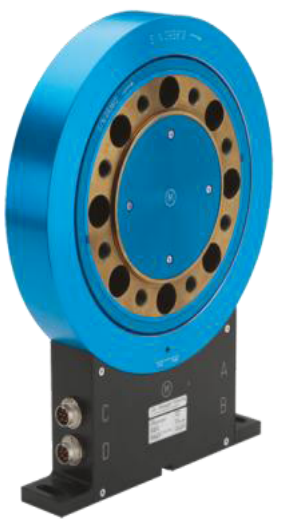

Figure 2. Kistler 4504B measuring flange [2] 


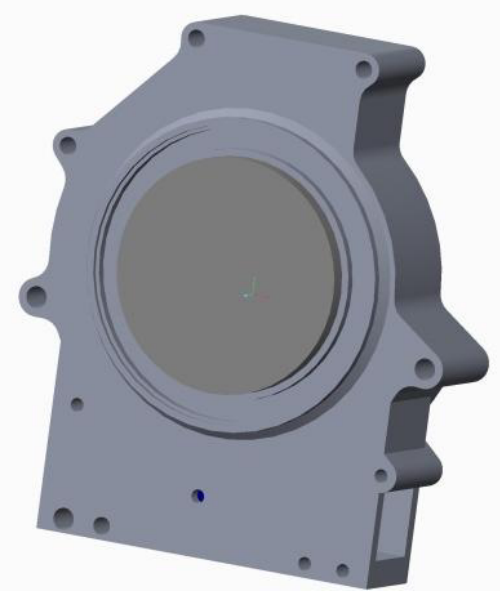

Figure 3. Model of measuring device [6]

\subsection{Sensor installation}

In order to define the space required for installing the measuring flange, we selected a very simple method using composite steel sheet fragments. This is a test design so it is possible to consider a case made from aluminium alloy in the future. The measuring flange is designed by the manufacturer to be subjected to torsional stress only, any other stresses are not permitted. Therefore, the whole system is mounted inside a ball bearing, which captures the axial forces from the clutch disengagement and possible radial forces from the bending stress of the system due to its own weight. [5] Measuring device is designed that by adding another rotating mass into crank shaft it follows that is necessary to remove some material from it for gain get acceptable inertia moment.

Table 1. Moment of inertia.

\begin{tabular}{|c|c|c|}
\hline & $\begin{array}{c}\text { Moment of } \\
\text { inertia } \\
\mathrm{I}\left[\mathrm{Kg}^{*} \mathrm{~m}^{2}\right]\end{array}$ & $\begin{array}{c}\text { Weight } \\
\mathrm{m}[\mathrm{Kg}]\end{array}$ \\
\hline flange of crank shaft & 0.00452 & 1.135 \\
\hline sensor & 0.01164 & 1.100 \\
\hline flange of flying wheel & 0.01106 & 2.850 \\
\hline bearing & 0.00707 & 0.910 \\
\hline original flying wheel & 0.073 & 6.521 \\
\hline adjusting flying wheel & 0.03871 & 4.157 \\
\hline
\end{tabular}

To put measuring element into measuring track, between engine and transmission, is necessary to create the case enough which will be a part of the engine. For quite simple manufacture, case is made if you like assembled from several pieces of plasma cut metal sheet. This is just first version of case but in future in could be made by aluminum casting.

The construction of torque sensor doesn't allow any other stress except torsion stress. Therefore is necessary to put bearing into assembly which avoids bending stress and axial stress caused by hydraulic clutch. This type of case construction brings just torque stress on torque sensor along with zero axial stress.

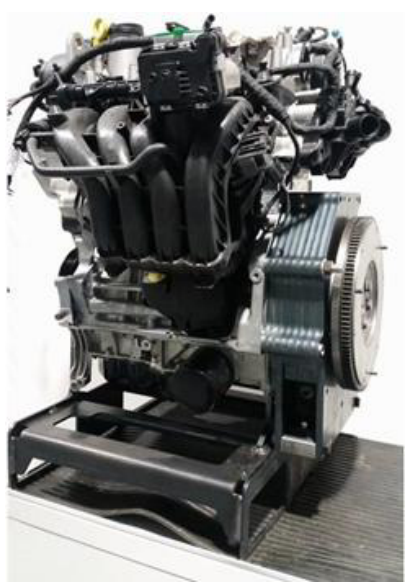

Figure 4. Overall view of the measurement elements mounted on the engine. [3]

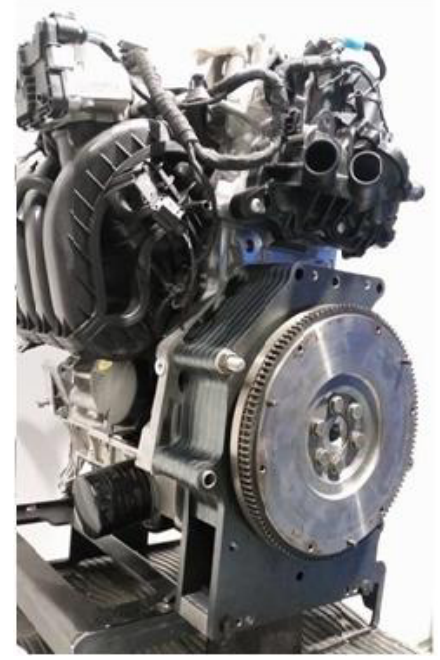

Figure 5. Overall view of the measurement elements mounted on the engine. [3]

\section{Experiment}

The experimental work was carried out on a supercharged EA 211 1, 4 TSI engine fitted with a sensor for measuring the pressure inside the cylinders, and the torque, which is measured directly on the crankshaft. The development of the individual variables was displayed and processed using an AVL Indicom 619 signalling device. Along with the above engine parameters, the courses of the signals on the ignition modules and the fuel injectors were measured using the clamp probes. With an engine set up in this way, it is possible to obtain an overview of all of the required parameters.

The tested engine was mounted on the test bed with an ASD 235 electric asynchronous dynamometer. The required and measured parameters are monitored and fully controlled by a desktop computer. To ensure safe operation of the engine, other engine parameters such as temperature and pressure of running fluids were also monitored. 
Table 2. Construction parameters of engine.

\begin{tabular}{|c|c|}
\hline Type of engine & EA 211, 2xOHC \\
\hline Bore $x$ stroke & $74.5 \times 80 \mathrm{~mm}$ \\
\hline No. of valves & 4 \\
\hline Type of fuel & $\begin{array}{c}\text { Direct fuel injection with } \\
\text { supercharging }\end{array}$ \\
\hline Compression ratio & $10.5: 1$ \\
\hline Volume & $1398 \mathrm{ccm}$ \\
\hline Maximum power output & $103 \mathrm{~kW}$ \\
\hline Maximum torque & $250 \mathrm{Nm}$ \\
\hline
\end{tabular}

During the measurement it was necessary to take into account the torque sensor, which is designed to be used up to $4,000 \mathrm{rpm}$. The engine already has a high torque at $1,000 \mathrm{rpm}$ due to its construction and supercharging. With respect to the above facts, the experiment was performed at revolutions of between 1,000 rpm and 3,500 rpm. In terms of torque, it had to be ensured that the maximum torque the sensor is designed for is not exceeded, which in this case was $1,000 \mathrm{Nm}$. It may seem that if the maximum torque of the sensor is 4 times greater than the engine torque, then the safety of the measurement is considerable, but the opposite is true. The maximum engine torque is only an effective value, the peak torque is many times greater. Therefore, a maximum torque of $200 \mathrm{Nm}$ was chosen during the experiment.

Table 3. Operating engine speed during experiment.

\begin{tabular}{|l|l|l|l|l|l|}
\hline \multicolumn{5}{|c|}{ Measurement of engine revolutions [RPM] } \\
\hline 1000 & 1250 & 1500 & 1750 & 2000 & 2250 \\
\hline 2500 & 2750 & 3000 & 3250 & 3500 & \\
\hline
\end{tabular}

Table 4. Engine load per operating engine speed.

\begin{tabular}{|l|l|l|l|l|l|l|l|l|l|}
\hline \multicolumn{1}{|c|}{ Measurement of engine load [Nm] } \\
\hline 5 & 10 & 25 & 50 & 75 & 100 & 125 & 150 & 175 & 200 \\
\hline
\end{tabular}

The basic assumption of the whole measurement was verification of the function of the designed torque sensor and the measurement of the effective and indicated parameters of the engine for the detection of the torque of the engine and the influence of the load on the measurement of the torque.

Figure 3 shows the course of the loss moment obtained from the effective torque measured using an asynchronous dynamometer. Figure 4 shows the course of the loss moment obtained by measuring the torque directly on the crankshaft

\section{Results}

From the measured data, it was possible to plot the course of the torque depending on the engine load. The following figures display data from both methods of measurement.

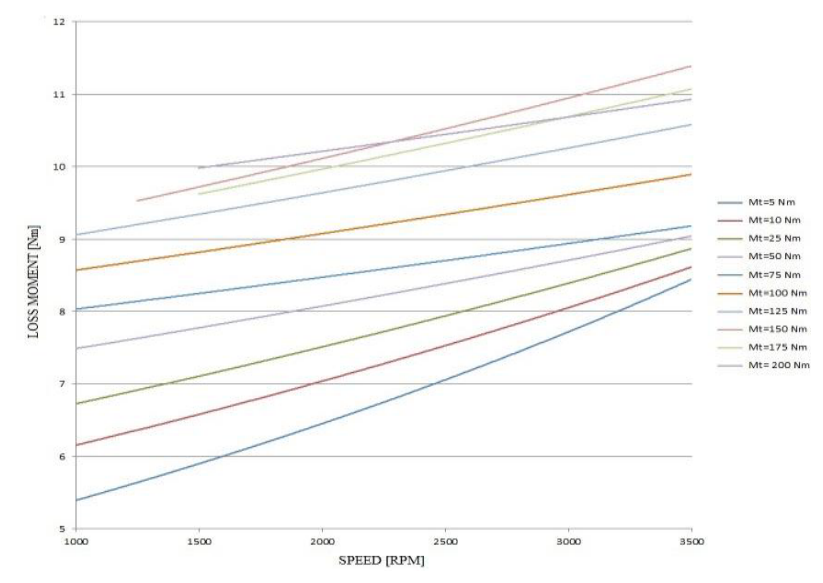

Figure 3. The rate of Loss moment in relation to the engine revolutions

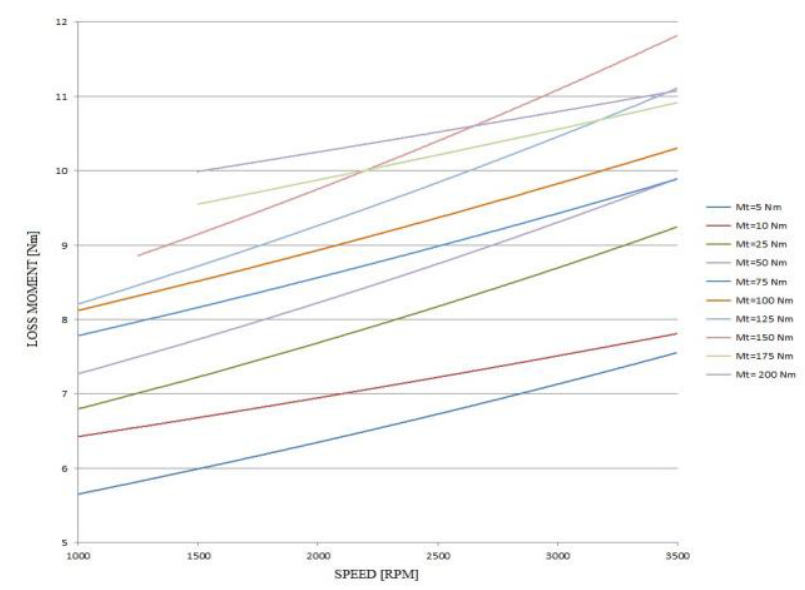

Figure 4. The rate of Loss moment in relation to the engine revolutions

\section{Conclusion}

During the experimental work, combustion pressures were measured at different revolutions and with different engine loads. The engine torque was measured in two ways. Firstly, by a torque sensor, which is part of the dynamometer? Secondly by measuring the torque directly on the engine's crankshaft. During the measurements, both methods showed quite similar results. The problem is that data is offset due to possible inappropriate setting of the measuring flange. Further research will be focussed on clarifying this phenomenon. After clarifying the difference in the measured values, it will be possible to evaluate the overall accuracy of the measurement method. Despite this phenomenon, the method of measuring the torque directly on the crankshaft was found to be very accurate and can be used for further experimental work.

\section{Acknowledgements}

The results of this project LO1201 were obtained through the financial support of the Ministry of Education, Youth and Sports in the framework of the targeted support of the "National Programme for Sustainability I" and the 
OPR\&DI project Centre for Nanomaterials, Advanced Technologies and Innovation CZ.1.05/2.1.00/01.0005

\section{References}

1. Ďado Stanislav, Kreidl Marcel; SENZORY a měřicí obvody, Praha 1996

2. www.Kistler.com
3. Popelka Josef; Návrh zařízení pro analýzu průběhu momentu mezi motorem a převodovým ústrojím automobilu, Závěrečná zpráva SGS; Liberec 2016

4. Vinklář Jiř́i; semestrální práce, Projekt II, Liberec, 2010

5. Popelka Josef; Metody měření točivého momentu spalovacích motorů, Harrachov 2015

6. Popelka, Mikulanin, Scholz; Construction of the measuring device for analyzing the torque of internal combustion engine, Saint Petersburg 2015 